Article

\title{
Facile Synthesis of Highly Conductive Vanadium-Doped NiO Film for Transparent Conductive Oxide
}

\author{
Ashique Kotta $\unrhd$ and Hyung Kee Seo * \\ Multifunctional Hybrid Nanomaterials Laboratory, School of Chemical Engineering, Jeonbuk National \\ University, Jeonju 54896, Korea; kottaash@jbnu.ac.kr \\ * Correspondence: hkseo@jbnu.ac.kr
}

Received: 3 July 2020; Accepted: 31 July 2020; Published: 5 August 2020

\begin{abstract}
Metal-oxide-based electrodes play a crucial role in various transparent conductive oxide (TCO) applications. Among the p-type materials, nickel oxide is a promising electrically conductive material due to its good stability, large bandgap, and deep valence band. Here, we display pristine and 3 at.\%V-doped $\mathrm{NiO}$ synthesized by the solvothermal decomposition method. The properties of both the pristine and 3 at. $\% \mathrm{~V}: \mathrm{NiO}$ nanoparticles were characterized by field emission scanning electron microscopy (FESEM), transmission electron microscopy (TEM), X-ray diffractometry (XRD), Raman spectroscopy, ultraviolet-visible spectroscopy (UV-vis), and X-ray photoelectron spectroscopy (XPS). The film properties were characterized by atomic force microscopy (AFM) and a source meter. Our results suggest that incorporation of vanadium into the $\mathrm{NiO}$ lattice significantly improves both electrical conductivity and hole extraction. Also, 3 at.\% $\mathrm{V}: \mathrm{NiO}$ exhibits a lower crystalline size when compared to pristine nickel oxide, which maintains the reduction of surface roughness. These results indicate that vanadium is an excellent dopant for $\mathrm{NiO}$.
\end{abstract}

Keywords: vanadium doping; size tuning; bandgap; transparent conductive oxide; electrical conductivity

\section{Introduction}

Nickel oxide $(\mathrm{NiO})$ is one of the rare metal oxide semiconductors, exhibiting a wide bandgap of $\sim 3.6 \mathrm{eV}$ [1-3]. It has been used in numerous practical applications, such as organic light-emitting diodes [4], sensors [5], supercapacitors [6], and solar cells [7]. There are many literature reports available on the synthesis of $\mathrm{NiO}$ nanoparticles (NPs) [8-11]. However, there have been difficulties in preparing a well-dispersed ultra-small $\mathrm{NiO}$ ink for transparent conductive oxide (TCO) applications $[12,13]$. In reality, electrode fabrication using pre-annealed $\mathrm{NiO}$ nanoparticles is difficult due to their lower dispersibility and poor adhesion on TCO substrates. Capping agents like oleylamine and oleic acid added during the synthesis of the metal oxide are beneficial for the suppression of particle growth and can eventually result in monodispersed metal oxide nanoparticles with great dispersion in DI water.

In recent reports, $\mathrm{NiO}$ has been used as a hole transport layer (HTL) in inverted perovskite solar cells [14-16] and organic light-emitting diodes (LEDs) [17]. In principle, to enhance the performance of solar cells and OLEDs, one needs to meet the following general requirements: better electrical conductivity, efficient charge transport, solution processing under low temperature, and bandgap tuning [18]. Improved electrical conductivity and hole extraction can be achieved through doping [19]. Different dopants have been used to improve the conductivity of $\mathrm{NiO}$, such as $\mathrm{Cs}$ [19], $\mathrm{Cu}$ [20], $\mathrm{Nb}$ [21], Y [22], Ag [1-24], Co [25], N [26], and K [27]. Among all these dopants, $\mathrm{Cu}$ is widely used for light doping in various TCO-based applications. 
In a study of $\mathrm{Ag}_{x} \mathrm{Ni}_{\mathrm{x}} \mathrm{O}$ film, Jun-Dar et al. reported that the $\mathrm{Ni}^{+3} / \mathrm{Ni}^{+2}$ ratio was enhanced by varying concentrations of $\mathrm{Ag}$ content [23]. They also reported that an increased $\mathrm{Ni}^{+3} / \mathrm{Ni}^{+2}$ ratio significantly increased the hole concentration. Another study by Sharma R et al. reported that the hole concentration of $\mathrm{NiO}$ is enhanced by light $\mathrm{Ag}$ doping, and the product was applied in heterojunction diodes (HJDs) [24].

A notable study by Wei Chen et al. [20] demonstrated that $\mathrm{Cu}$ doping on $\mathrm{NiO}$ drastically enhances the electrical conductivity of $\mathrm{NiO}$. More recently, Julien et al. reported that $\mathrm{N}$-doped $\mathrm{NiO}$ showed improved conductivity as compared to undoped $\mathrm{NiO}$ due to the influence of $\mathrm{Ni}$ vacancies [26]. The work of Islam et al. also demonstrated $\mathrm{NiO}$ film with superior conductivity due to a higher ratio of $\mathrm{Ni}^{3+}$ to $\mathrm{Ni}^{2+}$ [28].

In this work, for the first time (to the best of our knowledge), we studied the optical, morphological, and electrical conductivity properties of $\mathrm{V}: \mathrm{NiO}$ nanoparticles. Our main aim is to investigate how to modify $\mathrm{NiO}$ film conductivity on the TCO substrate. So, we substituted $\mathrm{Ni}$ with varying atomic percentages of vanadium in the $\mathrm{NiO}$ lattice. A comparative study of pristine $\mathrm{NiO}$ and 3 at. $\% \mathrm{~V}: \mathrm{NiO}$ showed improvements in film morphology and conductivity for 3 at. $\% \mathrm{~V}: \mathrm{NiO}$ as compared to pristine $\mathrm{NiO}$ film. Both the pristine and $\mathrm{V}$-doped $\mathrm{NiO}$ were prepared by the solvothermal decomposition method. Ultra-small-sized, highly crystalline, pre-annealed nanoparticles were used for deposition on the TCO substrate. However, the effect of vanadium doping on $\mathrm{NiO}$ has not been widely studied.

\section{Materials and Methods}

\subsection{Materials and Methods}

Materials, including Ni (II) acetylacetonate $\left(\mathrm{C}_{10} \mathrm{H}_{14} \mathrm{NiO}_{4}\right)$, oleylamine $\left(\mathrm{C}_{18} \mathrm{H}_{37} \mathrm{~N}\right)$, borane tri-ethylamine $\left[\left(\mathrm{C}_{2} \mathrm{H}_{5}\right)_{3} \mathrm{NBH}_{3}\right]$, and vanadium pentoxide $\left(\mathrm{V}_{2} \mathrm{O}_{5}\right)$, were purchased from Sigma-Aldrich.

\subsection{Characterization}

The properties of both pristine and vanadium-doped $\mathrm{NiO}(\mathrm{V}: \mathrm{NiO})$ nanoparticles were characterized by field emission scanning electron microscopy (FESEM, Hitachi S-4700, Tokyo, Japan), transmission electron microscopy (TEM, JEM-2010-JEOL, Tokyo, Japan), X-ray diffractometry (XRD, PANalytical X'Pert PRO, Almelo, The Netherlands), Raman spectroscopy (Renishaw, UK), ultraviolet-visible spectroscopy (UV-vis, Jasco V-670, Easton, MD, USA), and X-ray photoelectron spectroscopy (XPS, AXIS-NIVA CJ 109, Kratos, Manchester, UK). The film properties were characterized by tapping-mode atomic force microscopy (Bruker, Multimode-8, Billerica, MA, USA) and a source meter (Keithley-2450, Beaverton, OR, USA).

\subsection{Synthesis of Pristine and $\mathrm{V}$-Doped $\mathrm{NiO}$}

Nickel oxide $(\mathrm{NiO})$ nanoparticles were synthesized by the solvothermal decomposition method. Briefly, $1 \mathrm{mmol}$ of $\mathrm{Ni}(\mathrm{II})$ acetylacetonate was dissolved in $15 \mathrm{~mL}$ of oleylamine. The solution was kept in a two-necked round flask and heated to $110^{\circ} \mathrm{C}$ with continuous stirring under nitrogen flow for $45 \mathrm{~min}$. The obtained clear blue solution was then cooled to and maintained at $90^{\circ} \mathrm{C}$. Next, a mixture of $0.4 \mathrm{~mL}$ of borane tri-ethylamine and $2 \mathrm{~mL}$ oleylamine was quickly injected into the clear solution. The resulting dark solution was continuously stirred for $1 \mathrm{~h}$. The resultant solution containing ultra-small-sized $\mathrm{NiO}$ nanoparticles was collected via $6000 \mathrm{rpm}$ centrifugation for $15 \mathrm{~min}$. Then, the NPs were washed in ethanol three times. To obtain the vanadium-doped $\mathrm{NiO}(\mathrm{V}: \mathrm{NiO})$, different atomic percentages of vanadium pentoxide were added to the initial $\mathrm{Ni}(\mathrm{II})$ acetylacetonate and oleylamine solution. All other conditions were similar to those for the synthesis of the pristine NiO. In this reaction, oleylamine acts as a capping agent, which helps to reduce particle growth, and borane tri-ethylamine was used as a reducing agent, as shown in Scheme 1. As-synthesized pristine $\mathrm{NiO}$ and $\mathrm{V}: \mathrm{NiO}$ were easily dispersed in DI water by 30 min ultra-sonication. Pristine and doped $\mathrm{NiO}$ films were deposited under 
room temperature on cleaned FTO glass substrates by spin coating ( $2500 \mathrm{rpm}, 60 \mathrm{~s}$ ) with the solutions mentioned above.

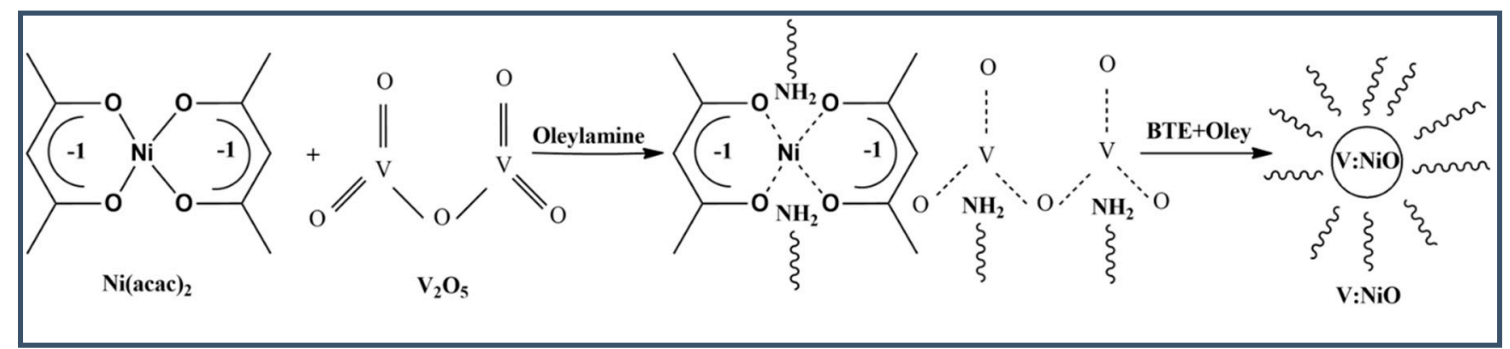

Scheme 1. Synthesis of $\mathrm{V}: \mathrm{NiO}$ nanoparticles by solvothermal decomposition of a V:Ni-oleylamine complex.

\section{Results}

\subsection{Study of Material Properties}

To study the effect of $\mathrm{V}$ doping on $\mathrm{NiO}$, the materials were subjected to analysis using XRD. In our work, both pristine and 3 at.\%V:NiO NPs exhibited a very broad XRD pattern (Figure 1a). The diffraction peaks of the prepared powder samples show a cubic face-centered crystal system with four characteristic diffraction peaks at $2 \theta=36.98^{\circ}, 43.21^{\circ}, 62.67^{\circ}$, and $75.34^{\circ}$, which could be assigned to the (111), (200), (220), and (311) planes of NiO, respectively. The synthesized NiO NP formation was confirmed using the Joint Committee on Powder Diffraction Standards (JCPDS) card no. 03-065-2901 with space group Fm3m [29]. Meanwhile, no extra diffraction peaks related to vanadium or vanadium oxide were observed. A similar trend was also observed for the 1.5 at. $\% \mathrm{~V}: \mathrm{NiO}$ sample, but an extra diffraction peak of $\mathrm{V}_{2} \mathrm{O}_{5}$ was observed at a higher doping percentage ( $\left.5 \mathrm{at} . \% \mathrm{~V}: \mathrm{NiO}\right)$. This result indicates that a light doping concentration of $\mathrm{V}$ hardly changes the phase structure of $\mathrm{NiO}$ [2]. Additionally, it could be observed that the 3 at. $\% \mathrm{~V}: \mathrm{NiO}$ NP diffraction peak at $43.251^{\circ}$ shows a broadening and slight shifting towards a higher angle (Figure $1 \mathrm{~b}$ ). This result indicates the incorporation of vanadium into the $\mathrm{NiO}$ lattice. It is also important to mention that the diffraction peak broadening of the 3 at. $\% \mathrm{~V}: \mathrm{NiO}$ sample reveals the reduction of particle size. To further understand the effect of particle size after doping, we calculated the crystalline size of both samples by the Debye-Scherrer formula, $D_{p}=\frac{0.89 \lambda}{\cos }$, where $D_{p}$ is the crystalline size, $\lambda$ is the $X$-ray wavelength, $\beta$ is the full width at half-maximum (FWHM), and $\theta$ is the diffraction angle of the peak. Interestingly, we observed that the crystalline size of peak (200) significantly decreased after doping from $3.09 \mathrm{~nm}$ to $2.82 \mathrm{~nm}$. Hence, the dissociation density $(\delta)$ and lattice strain $(\varepsilon)$ were calculated by the equations $[30]=\frac{1}{D_{p}{ }^{2}}$ and $=\cos / 4$, and values are tabulated in Table 1 . It can be concluded that the $\mathrm{NiO}$ crystalline size was decreased by $\mathrm{V}$ doping; thereby, the dissociation density and lattice strain were enhanced.

Figure 2a shows the FTIR spectra of $\mathrm{Ni}(\mathrm{ac})_{2}, \mathrm{~V}_{2} \mathrm{O}_{5}, \mathrm{NiO}$, and 3 at.\% $\mathrm{V}: \mathrm{NiO}$ for a comparative study of the precursor materials and products. In our case, the characteristic stretching vibration of the $\mathrm{Ni}-\mathrm{O}$ absorption band was observed at $468 \mathrm{~cm}^{-1}$, which originated from the $\mathrm{Ni}(\mathrm{ac})_{2}$ species. The peak at $676 \mathrm{~cm}^{-1}$ in the doped sample was ascribed to the presence of vanadium. We observed that the $\mathrm{Ni}-\mathrm{O}$ stretching band in $\mathrm{NiO}$ and the $\mathrm{V}-\mathrm{O}-\mathrm{V}$ stretching band in the 3 at.\% $\mathrm{V}: \mathrm{NiO}$ sample were shifted to lower wavenumber regions as compared with the $\mathrm{Ni}(\mathrm{ac})_{2}$ and $\mathrm{V}_{2} \mathrm{O}_{5}$ precursor samples. These red shifts are associated with changes in the surface area and surface defects due to the oleylamine (capping agent) added during the synthesis. 
Table 1. Measured values of structural parameters for $\mathrm{NiO}$ and $\mathrm{V}: \mathrm{NiO}$.

\begin{tabular}{cccccccc}
\hline Samples & $\left.\mathbf{2 \theta} \mathbf{(}^{\circ}\right)$ & $\mathbf{h k 1}$ & $\mathbf{F W H M}$ & $\mathbf{d}_{\mathbf{s p}}\left(\mathbf{A}^{\circ}\right)$ & $\mathbf{D}_{\mathbf{p}}(\mathbf{n m})$ & $\delta\left(\mathbf{n m} \mathbf{1}^{\mathbf{1}}\right)$ & $\varepsilon \times \mathbf{1 0}^{-\mathbf{2}}$ \\
\hline $\mathrm{NiO}$ & 43.251 & 200 & 2.94 & 2.095 & 3.04 & 0.1082 & 0.955 \\
3 at.\%V:NiO & 43.278 & 200 & 3.17 & 2.094 & 2.82 & 0.1257 & 1.054 \\
\hline
\end{tabular}
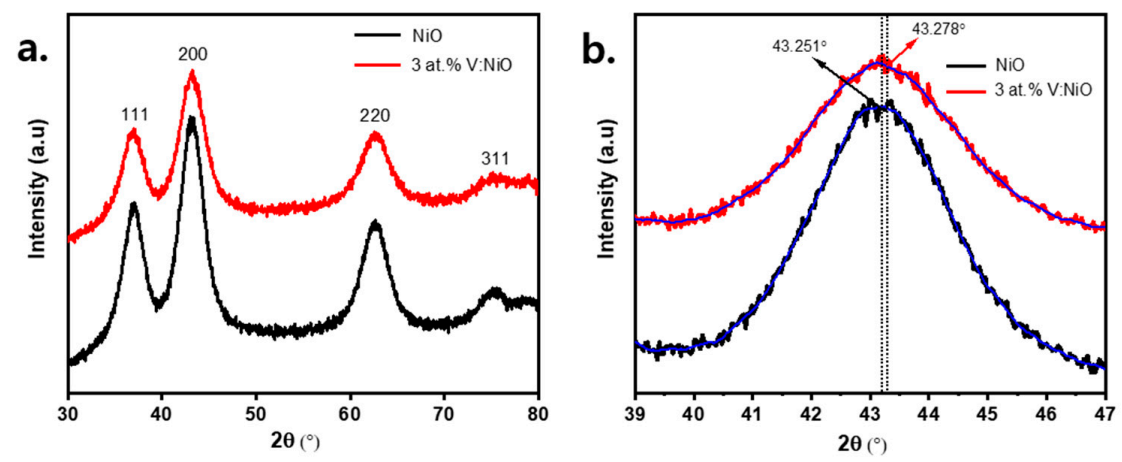

Figure 1. (a) XRD spectra of pristine and 3 at.\%V:NiO nanoparticles (NPs) and (b) enlarged XRD spectra of pristine $\mathrm{NiO}$ and 3 at.\%V:NiO NPs.

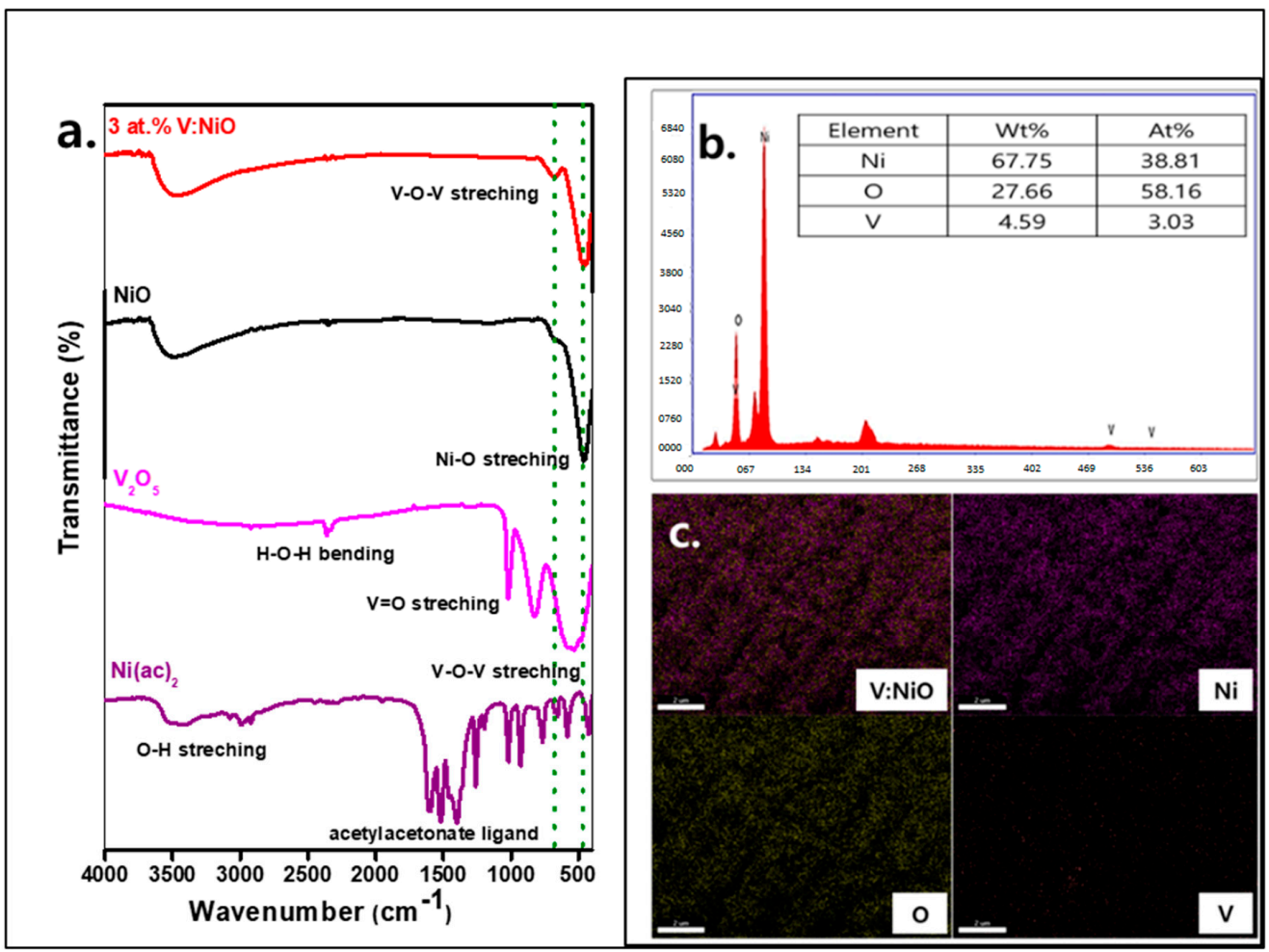

Figure 2. (a) FTIR spectra of $\mathrm{NiO}$ and 3 at. $\% \mathrm{~V}: \mathrm{NiO}$ with precursor materials, (b) EDS spectra of 3 at.\% $\mathrm{V}: \mathrm{NiO} \mathrm{NPs}$, and (c) EDS elemental mapping of the corresponding elements of $\mathrm{Ni}, \mathrm{O}$, and $\mathrm{V}$ (scale bar, $2 \mu \mathrm{m}$ ).

The elemental compositions of both the pristine and 3 at.\%V:NiO NPs were confirmed by energy-dispersive $\mathrm{X}$-ray spectroscopy (EDAX). Figure $2 \mathrm{~b}$ shows that the 3 at. $\% \mathrm{~V}: \mathrm{NiO}$ powder sample consisted of $\mathrm{Ni}, \mathrm{V}$, and $\mathrm{O}$ with no impurity elements. The weight and atomic percentage values of the $\mathrm{Ni}, \mathrm{O}$, and $\mathrm{V}$ elements are given in the inset of Figure 2b. The EDX mapping of elements in Figure $2 \mathrm{c}$ revealed the uniform distribution of $\mathrm{Ni}, \mathrm{V}$, and $\mathrm{O}$ in the sample. 
The Raman spectra of $\mathrm{NiO}$ and 3 at.\%V:NiO are given in Figure 3a. From the analysis, four characteristic Raman peaks were positioned in both samples, corresponding to the shaking peaks of $\mathrm{NiO}$. The peaks at 324 and $479 \mathrm{~cm}^{-1}$ are the first-order transverse optical (TO) and longitudinal optical (LO) phonon modes of NiO NPs, respectively. The peaks at 546 and $686 \mathrm{~cm}^{-1}$ are because of the combination of 2TO and 2LO. Meanwhile, an extra peak observed at $760 \mathrm{~cm}^{-1}$ can be associated with the $\mathrm{V}-\mathrm{O}$ stretching mode in the 3 at.\% V:NiO sample. This result shows that vanadium can be incorporated with oxygen.

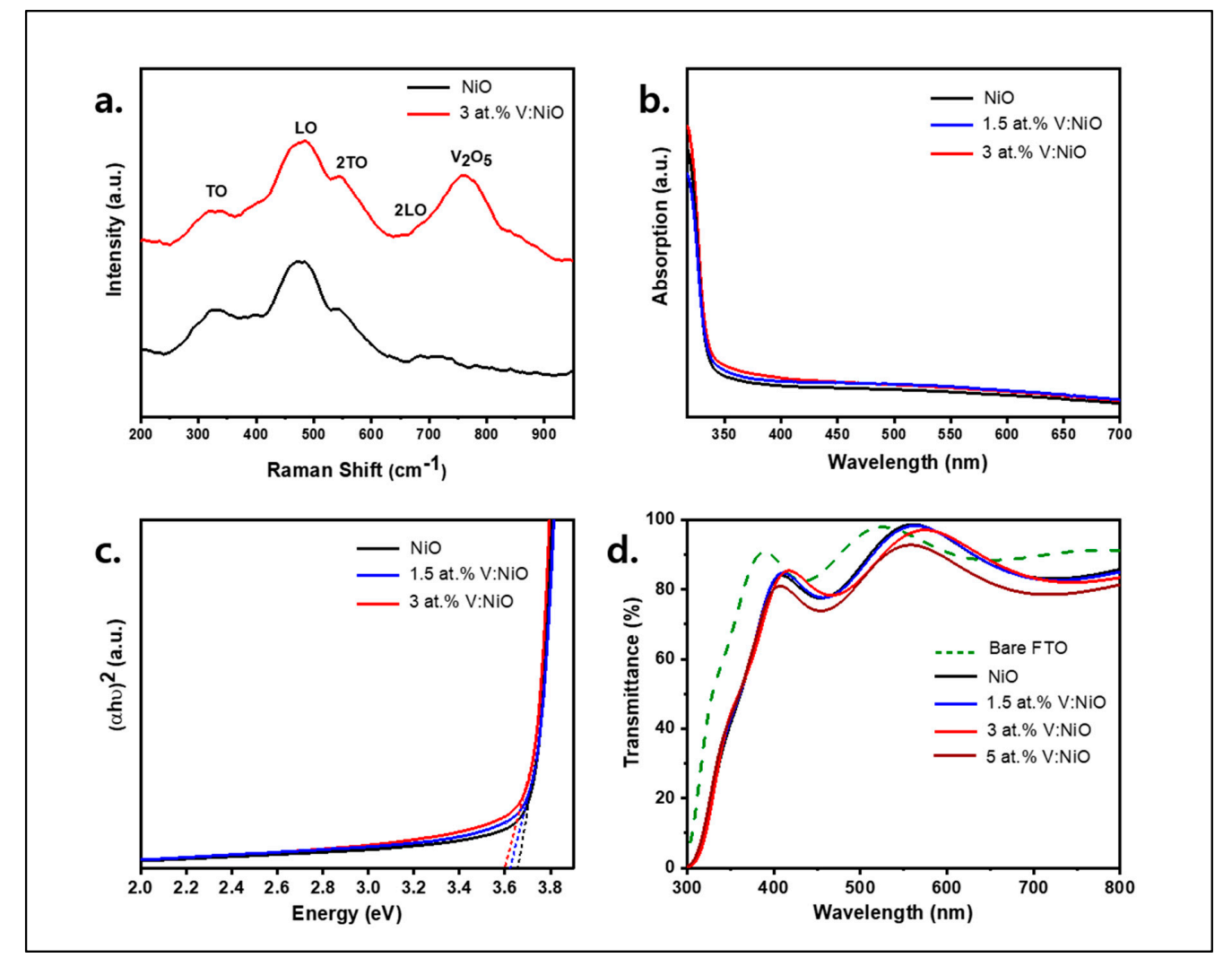

Figure 3. (a) Raman spectra of $\mathrm{NiO}$ and 3 at.\% V:NiO NP powder samples; (b) UV-absorption spectra of diluted $\mathrm{NiO}$ and $\mathrm{V}: \mathrm{NiO} \mathrm{NP}$ solutions with different atomic percentages of $\mathrm{V}$; (c) Corresponding Tauc plots of the absorption spectra; (d) Optical transmission spectra of $\mathrm{NiO}$ and $\mathrm{V}: \mathrm{NiO}$ films with different atomic percentages of $\mathrm{V}$.

Figure 3b, c depicts the results of ultraviolet-visible spectroscopy studies of ethanol-dispersed pristine and doped $\mathrm{NiO}$ samples. A gradual red shift in the absorption spectra with increasing $\mathrm{V}$ concentration is observed from Figure $3 b$. This shift is consistent with the incorporation of $\mathrm{V}^{5+}$ into the $\mathrm{NiO}$ lattice. This indicates that the band gap energy in 3 at.\% $\mathrm{V}: \mathrm{NiO}$ is lower than that in pristine $\mathrm{NiO}$. Meanwhile, the optical band gap estimated for pristine NiO NPs by Tauc plot (Figure 3c) was around $3.65 \mathrm{eV}$, which is well matched with the previously reported values [2,3]. In NiO NPs doped with different percentages of $\mathrm{V}$, it was clear that after introducing vanadium content into the $\mathrm{NiO}$ crystal lattice, the optical band gap was slightly reduced to $3.62 \mathrm{eV}$ for $1.5 \mathrm{at} . \% \mathrm{~V}: \mathrm{NiO}$ and $3.59 \mathrm{eV}$ for 3 at.\%V:NiO.

It is important to study the optical transmission spectra of pristine $\mathrm{NiO}$ and $\mathrm{V}: \mathrm{NiO}$ films, shown in Figure 3d. Both $\mathrm{NiO}$ and V:NiO films coated on an FTO substrate still exhibited high transmission $(>80 \%)$ in the visible region. A small variation in transmission was observed for both 1.5 and 3 at.\%V:NiO films when compared to that for the pristine NiO. However, we also noticed that the optical transmittance decreased with increasing $\mathrm{V}$ doping percentage. $\mathrm{NiO}$ film with a higher doping percentage ( 5 at. $\% \mathrm{~V}: \mathrm{NiO}$ ) exhibited low transmission as compared to the pristine $\mathrm{NiO}$ film, while 
$\mathrm{V}: \mathrm{NiO}$ film with 3 at. $\% \mathrm{~V}$ doping content exhibited transmittance higher than $80 \%$ for the visible range. Therefore, the optimized V content of 3 at.\% for NiO NPs was used for further studies.

FESEM micrographs with higher-resolution images of pristine $\mathrm{NiO}$ and 3 at.\%V:NiO powder samples are shown in Figure 4a,b. The samples exhibit similar morphology with ultra-small-sized spherical structures that are agglomerated. TEM images showing the same sample morphology are displayed in Figure 4c,d. The particle diameters are summarized in Figure $4 \mathrm{~g}$. The statistical distributions of the nanoparticle diameters of pristine $\mathrm{NiO}$ and 3 at. $\% \mathrm{~V}: \mathrm{NiO}$ were measured to be $\sim 3.5$ $\pm 0.5 \mathrm{~nm}$ and $\sim 2.5 \pm 0.5 \mathrm{~nm}$, respectively. This result was consistent with the result of XRD. The particle size variations in the TEM analysis of both samples may be due to the influence of large Ni ions (ionic radius, $0.83 \mathrm{~A}^{\circ}$ ) replaced by small $\mathrm{V}$ ions (ionic radius, $0.72 \mathrm{~A}^{\circ}$ ). Meanwhile, the HRTEM results revealed that the interplanar distance of both samples in Figure $4 \mathrm{e}, \mathrm{f}$ was $0.21 \mathrm{~nm}$.

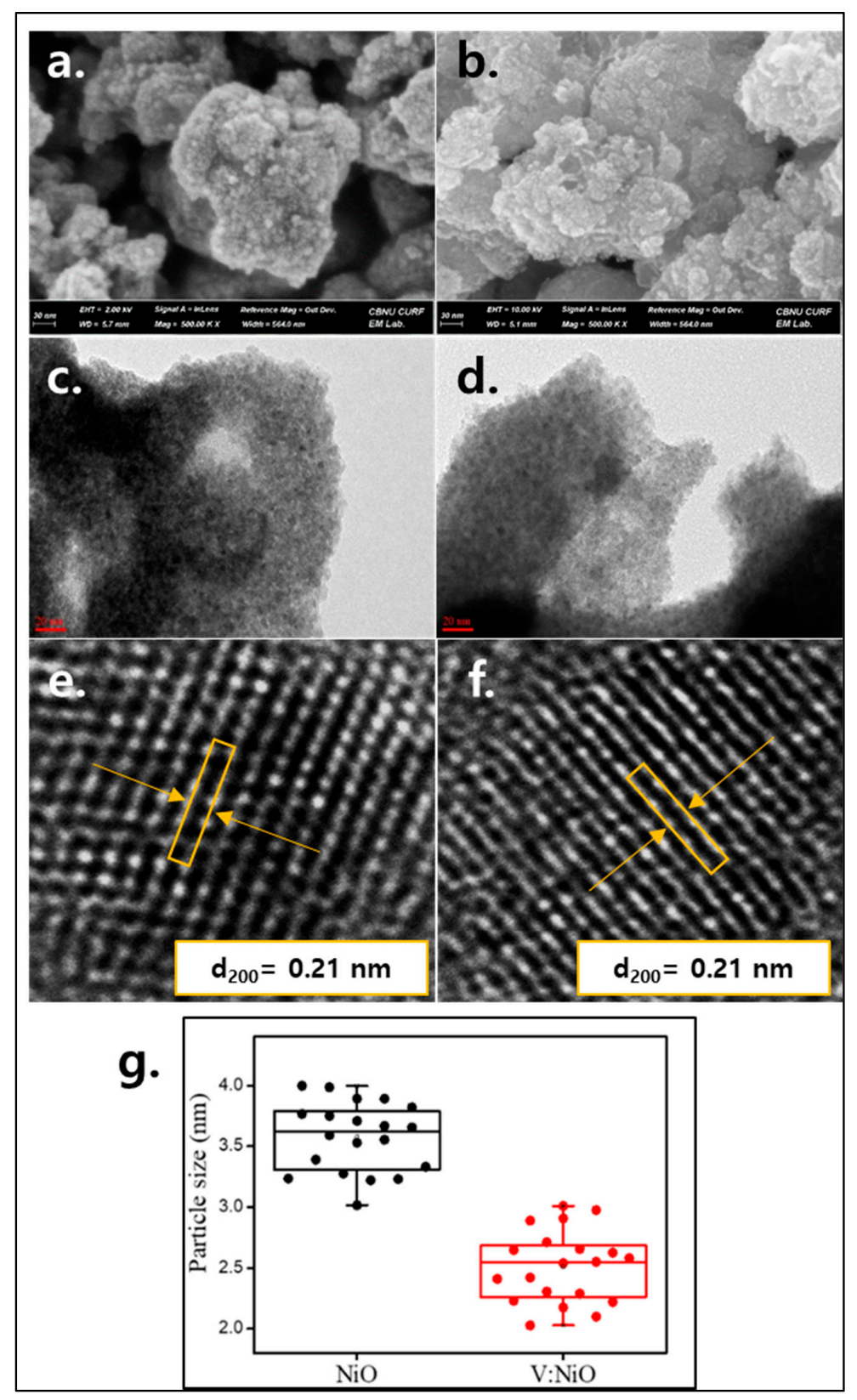

Figure 4. (a) FESEM images of (a) $\mathrm{NiO}$ and (b) 3 at.\%V:NiO and TEM patterns of (c) $\mathrm{NiO}$ and (d) 3 at.\%V:NiO. (e,f) HRTEM images of both (e) $\mathrm{NiO}$ and (f) 3 at.\% $\mathrm{V}: \mathrm{NiO}$ and (g) statistics of the particle distributions of $\mathrm{NiO}$ and 3 at.\% $\mathrm{V}: \mathrm{NiO}$ NPs. 
Elemental analysis was performed via X-ray photoelectron spectroscopy. The survey spectra of pristine $\mathrm{NiO}$ (Figure 5a) confirmed the presence of $\mathrm{Ni}$ and $\mathrm{O}$ elements, whereas $\mathrm{Ni}, \mathrm{O}$, and $\mathrm{V}$ elements were confirmed in the 3 at. $\% \mathrm{~V}: \mathrm{NiO}$ sample (Figure $5 \mathrm{~d}$ ). Typically, $\mathrm{NiO} 2 \mathrm{P}_{3 / 2}$ consists of a main peak at $854 \mathrm{eV}$, shoulder peak at $856 \mathrm{eV}$, and shake-up satellite peak at $861 \mathrm{eV}$ [31]. No major changes were observed in a comparison of the $\mathrm{Ni}_{2} \mathrm{P}_{3 / 2}$ spectra of both pristine and doped samples (Figure $5 \mathrm{~b}, \mathrm{e}$ ). However, in the case of the doped sample, we detected the presence of $\mathrm{V}^{4+}$ and $\mathrm{V}^{5+}$ in the binding energy range between $526 \mathrm{eV}$ and $510 \mathrm{eV}$, which reveals that $\mathrm{V}$ atoms were successfully incorporated into the $\mathrm{NiO}$ crystal lattice. Interestingly, after $\mathrm{V}$ occupied the interstitial sites in the $\mathrm{NiO}$ lattice, $\mathrm{Ni}^{3+}$ ions were possibly induced by $\mathrm{V}^{5+}$ ions (Figure 5e). Further, we calculated the $\mathrm{Ni}^{3+} / \mathrm{Ni}^{2+}$ ratios to be 0.96 and 1.04 for the $\mathrm{NiO}$ and 3 at.\%V:NiO samples, respectively. The higher density of $\mathrm{Ni}^{3+}$ states in the 3 at. $\% \mathrm{~V}: \mathrm{NiO}$ crystal would contribute to the improvement of p-type conductivity $[23,24,31]$.
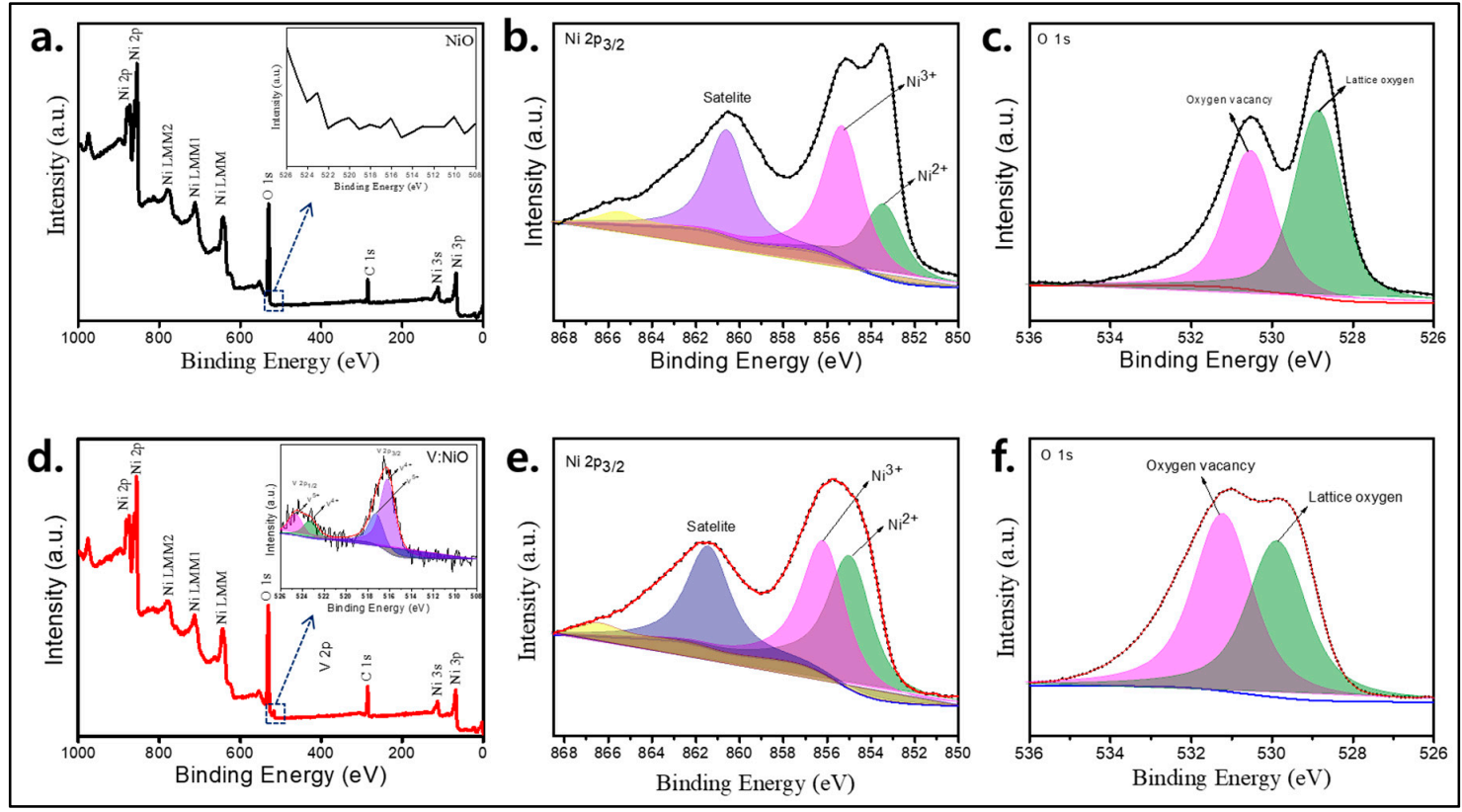

Figure 5. (a-c) XPS spectra of NiO: (a) survey spectra (inset: high-resolution spectra of V 2p), high-resolution (b) Ni 2 $\mathrm{p}_{3 / 2}$ and (c) O 1s; (d-f) XPS spectra of 3 at.\%V:NiO: (a) survey spectra (inset: high-resolution spectra of $\mathrm{V} 2 \mathrm{p}$ ), high-resolution (b) $\mathrm{Ni} 2 \mathrm{p}_{3 / 2}$ and (c) $\mathrm{O} 1 \mathrm{~s}$.

\subsection{Study of Film Properties}

The morphology of the surface of thin films of pristine $\mathrm{NiO}$ and 3 at.\%V:NiO was studied using atomic force microscopy. Figure $6 \mathrm{a}-\mathrm{d}$ shows AFM topography and three-dimensional (3D) images of $\mathrm{NiO}$ and 3 at.\% V:NiO on FTO substrates. A clear observation of particle size reduction was also confirmed by the AFM topographic images of 3 at. $\% \mathrm{~V}: \mathrm{NiO}$ film. Both the pristine and 3 at. $\% \mathrm{~V}: \mathrm{NiO}$ films showed a closely packed uniform morphology and exhibited root mean square (RMS) surface roughness values of $2.94 \mathrm{~nm}$ and $2.49 \mathrm{~nm}$, respectively. This reduction in surface roughness in the film after doping indicates that a small amount of vanadium in the $\mathrm{NiO}$ lattice will be beneficial for the various transparent conductive oxide applications $[1,17,20,22]$. 


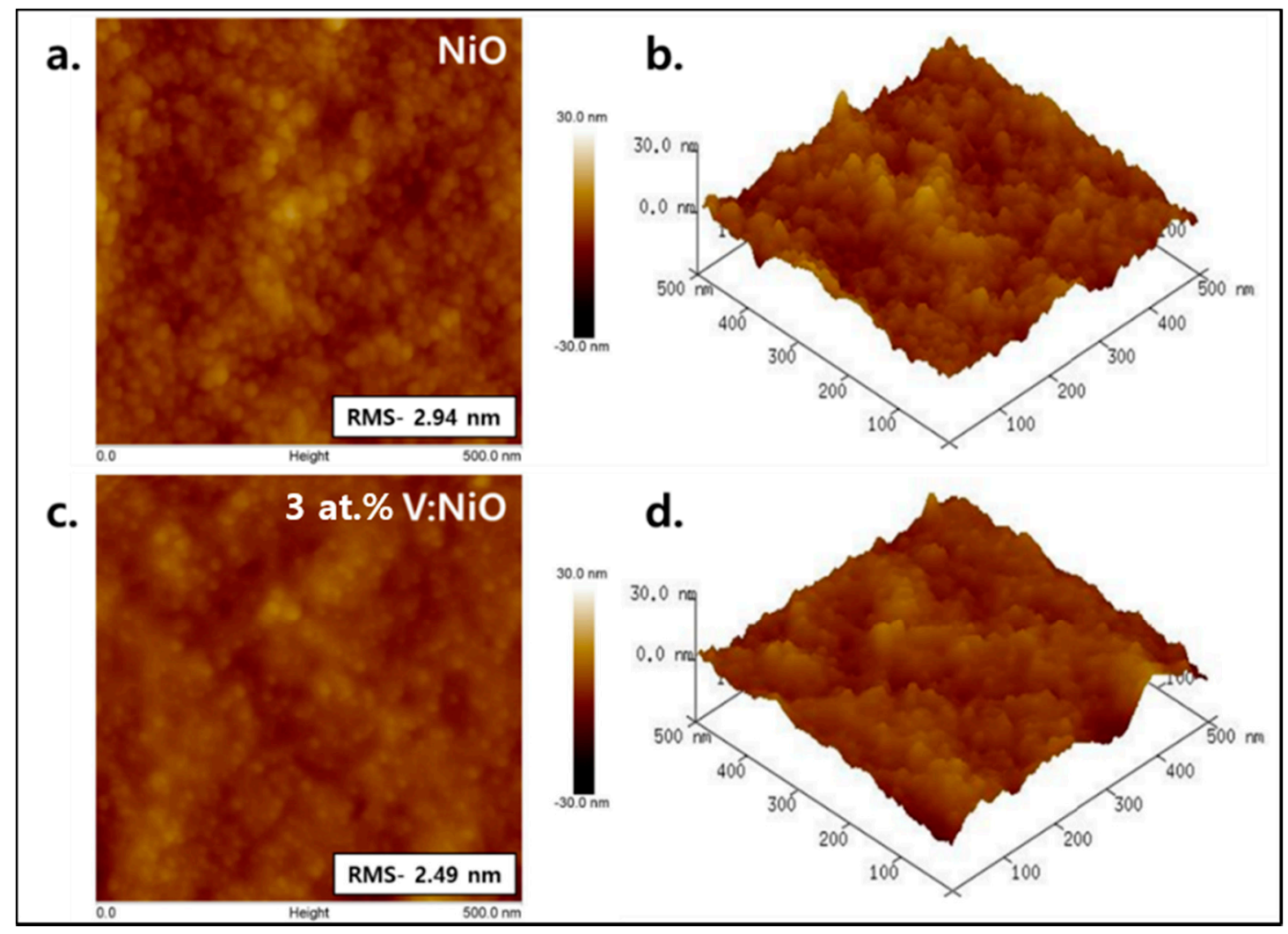

Figure 6. AFM topography and 3D AFM images of (a,b) NiO NPs and (c,d) 3 at.\%V:NiO.

We also investigated the influence of $\mathrm{V}$ doping on the electrical conductivity of the $\mathrm{NiO}$ thin films by a photovoltaic measurement system. For that, $20 \mathrm{mg} / \mathrm{mL} \mathrm{NiO}$ or 3 at.\%V:NiO dispersed in DI water was spin-coated onto a precleaned FTO substrate $(16 \Omega)$. Then, the substrates were annealed at $60{ }^{\circ} \mathrm{C}$ for $10 \mathrm{~min}$ to remove residual water. The electrodes were then transferred into a thermal evaporator (JVAC, South Korea) for the deposition of silver. The silver electrode (active area $0.2 \mathrm{~cm}^{2}$ ) was thermally evaporated with a thickness of $100 \mathrm{~nm}$ at a deposition rate of $0.4 \mathrm{~nm}$ per second through a shadow mask. The current-voltage (I-V) curves of the fabricated $\mathrm{FTO} / \mathrm{NiO}$ and 3 at. $\% \mathrm{~V}: \mathrm{NiO} / \mathrm{Ag}$ films were measured by a source meter. The following equation used to calculate the conductivity of the films:

$$
\sigma=\frac{d}{A \times R}
$$

where $\sigma$ is the conductivity, $\mathrm{d}$ is the thickness of the films, $\mathrm{A}$ is the active area, and $\mathrm{R}$ is the resistance obtained from the I-V curve. As shown in Figure 7, replacing the pristine $\mathrm{NiO}$ film with a 3 at.\% $\mathrm{V}: \mathrm{NiO}$ film significantly increased the vertical current, indicating the enhancement of electrical conductivity upon $\mathrm{V}$ doping. The conductivity values of the pristine $\mathrm{NiO}$ and 3 at. $\% \mathrm{~V}: \mathrm{NiO}$ films were estimated to be $2.9 \times 10^{-6} \mathrm{Scm}^{-1}$ and $3.9 \times 10^{-6} \mathrm{Scm}^{-1}$, respectively. The conductivity of 3 at. $\% \mathrm{~V}: \mathrm{NiO}$ film, compared to that of pristine $\mathrm{NiO}$ film, was enhanced by about $34.4 \%$ due to the enrichment of $\mathrm{Ni}^{3+}$ ions in the 3 at.\%V:NiO sample [25]. This point was extensively discussed in the XPS analysis. The previously reported values are within the range for $\mathrm{NiO}$ films depending on the film composition and deposition condition [32]. A recent work by Julien et al. observed the same trend of an increase in conductivity for nitrogen-doped $\mathrm{NiO}$ film $\left(2.8 \times 10^{-7} \mathrm{Scm}^{-1}\right)$ compared to pristine $\mathrm{NiO}$ film $\left(1.39 \times 10^{-7} \mathrm{Scm}^{-1}\right)$ [26]. Our results demonstrate that $\mathrm{V}$ doping can be a powerful way to control the electrical conductivity of $\mathrm{NiO}$. 


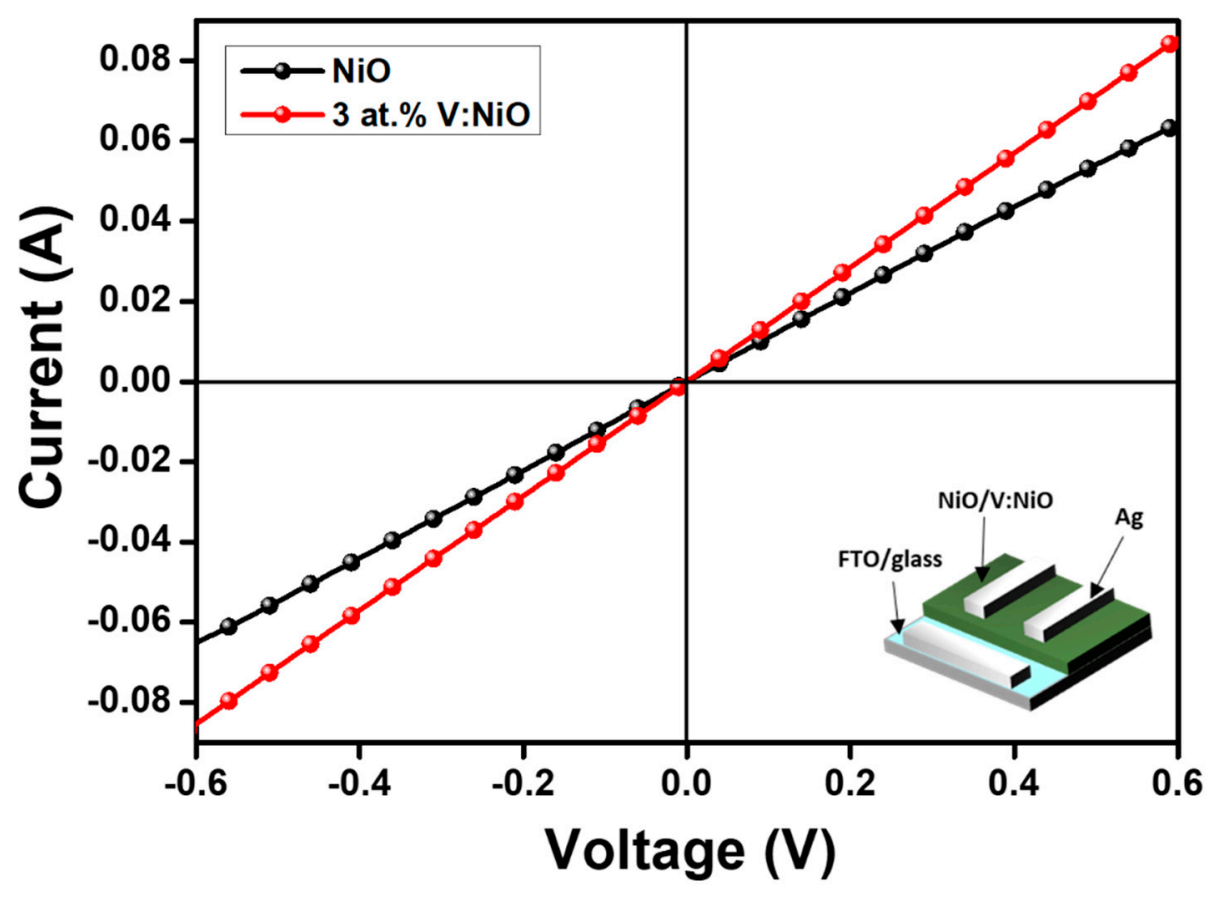

Figure 7. I-V curves of $\mathrm{NiO}$ and 3 at.\% $\mathrm{V}: \mathrm{NiO}$ films based on the structure of $\mathrm{FTO} / \mathrm{NiO}$ or 3 at. $\% \mathrm{~V}: \mathrm{NiO} / \mathrm{Ag}$; the inset shows the corresponding fabricated electrode structure.

\section{Conclusions}

In conclusion, pristine $\mathrm{NiO}$ and 3 at.\% vanadium (V)-doped $\mathrm{NiO}$ were successfully synthesized by a solvothermal decomposition method and deposited on an FTO substrate. The 3 at.\% V:NiO film exhibited a lower crystalline size when compared to pristine $\mathrm{NiO}$ film. A systematic crystallographic, optical, and morphological investigation showed that the $\mathrm{V}$ content in the $\mathrm{NiO}$ lattice would be beneficial for optoelectronic device applications. Also, AFM investigations of the 3 at. $\% \mathrm{~V}: \mathrm{NiO}$ showed that the root mean square (RMS) surface roughness was lowered in comparison to that of the pristine $\mathrm{NiO}$ film. Finally, I-V curves showed that the conductivity of the V:NiO film was effectively enhanced by about $34.4 \%$. The improvement of electrical conductivity can promote better charge transport and a reduction of interfacial charge accumulation.

Author Contributions: A.K. performed the experiments and wrote the manuscript. H.K.S. contributed to the preparation and revision of the manuscript. All authors have read and agreed to the published version of the manuscript.

Funding: This work was supported by a National Research Foundation of Korea (NRF) Project \#2018 R1A4A102552813 and Korea Basic Science Institute (National research Facilities and Equipment Center) grant funded by the Ministry of Education (grant 2020R1A6C101A204).

Conflicts of Interest: The authors declare no conflict of interest.

\section{References}

1. Zheng, J.; Hu, L.; Yun, J.S.; Zhang, M.; Lau, C.F.J.; Bing, J.; Deng, X.; Ma, Q.; Cho, Y.; Fu, W.; et al. Solution-Processed, Silver-Doped $\mathrm{NiO} x$ as Hole Transporting Layer for High-Efficiency Inverted Perovskite Solar Cells. ACS Appl. Energy Mater. 2018, 1, 561-570. [CrossRef]

2. Hu, L.; Peng, J.; Wang, W.; Xia, Z.; Yuan, J.; Lu, J.; Huang, X.; Ma, W.; Song, H.; Chen, W.; et al. Sequential Deposition of CH3NH3PbI3 on Planar NiO Film for Efficient Planar Perovskite Solar Cells. ACS Photonics 2014, 1, 547-553. [CrossRef] 
3. Zhai, Z.; Huang, X.; Xu, M.; Yuan, J.; Peng, J.; Ma, W. Greatly Reduced Processing Temperature for a Solution-Processed NiO x Buffer Layer in Polymer Solar Cells. Adv. Energy Mater. 2013, 3, 1614-1622. [CrossRef]

4. Im, H.C.; Choo, D.C.; Kim, T.W.; Kim, J.H.; Seo, J.H.; Kim, Y.K. Highly efficient organic light-emitting diodes fabricated utilizing nickel-oxide buffer layers between the anodes and the hole transport layers. Thin Solid Films 2007, 515, 5099-5102. [CrossRef]

5. Amin, S.; Tahira, A.; Solangi, A.; Mazzaro, R.; Ibupoto, Z.H.; Vomiero, A. A sensitive enzyme-free lactic acid sensor based on NiO nanoparticles for practical applications. Anal. Methods 2019, 11, 3578-3583. [CrossRef]

6. Vijayakumar, S.; Nagamuthu, S.; Muralidharan, G. Supercapacitor studies on NiO nanoflakes synthesized through a microwave route. ACS Appl. Mater. Interfaces 2013, 5, 2188-2196. [CrossRef]

7. Seo, S.; Park, I.J.; Kim, M.; Lee, S.; Bae, C.; Jung, H.S.; Park, N.G.; Kim, J.Y.; Shin, H. An ultra-thin, un-doped $\mathrm{NiO}$ hole transporting layer of highly efficient (16.4\%) organic-inorganic hybrid perovskite solar cells. Nanoscale 2016, 8, 11403-11412. [CrossRef]

8. Natarajan, C.; Matsumoto, H.; Nogami, G. Improvement in electrochromic stability of electrodeposited nickel hydroxide thin film. J. Electrochem. Soc. 1997, 144. [CrossRef]

9. Song, X.; Gao, L. Facile synthesis of polycrystalline $\mathrm{NiO}$ nanorods assisted by microwave heating. J. Am. Ceram. Soc. 2008, 91, 3465-3468. [CrossRef]

10. Šurca, A.; Orel, B.; Pihlar, B.; Bukovec, P. Optical, spectroelectrochemical and structural properties of sol-gel derived Ni-oxide electrochromic film. J. Electroanal. Chem. 1996, 408, 83-100. [CrossRef]

11. Wang, W.N.; Itoh, Y.; Lenggoro, I.W.; Okuyama, K. Nickel and nickel oxide nanoparticles prepared from nickel nitrate hexahydrate by a low pressure spray pyrolysis. Mater. Sci. Eng. B Solid-State Mater. Adv. Technol. 2004, 111, 69-76. [CrossRef]

12. Qiu, Z.; Gong, H.; Zheng, G.; Yuan, S.; Zhang, H.; Zhu, X.; Zhou, H.; Cao, B. Enhanced physical properties of pulsed laser deposited $\mathrm{NiO}$ films via annealing and lithium doping for improving perovskite solar cell efficiency. J. Mater. Chem. C 2017, 5, 7084-7094. [CrossRef]

13. Bai, Y.; Chen, H.; Xiao, S.; Xue, Q.; Zhang, T.; Zhu, Z.; Li, Q.; Hu, C.; Yang, Y.; Hu, Z.; et al. Effects of a Molecular Monolayer Modification of NiO Nanocrystal Layer Surfaces on Perovskite Crystallization and Interface Contact toward Faster Hole Extraction and Higher Photovoltaic Performance. Adv. Funct. Mater. 2016, 26, 2950-2958. [CrossRef]

14. Sun, J.; Lu, J.; Li, B.; Jiang, L.; Chesman, A.S.R.; Scully, A.D.; Gengenbach, T.R.; Cheng, Y.B.; Jasieniak, J.J. Inverted perovskite solar cells with high fill-factors featuring chemical bath deposited mesoporous $\mathrm{NiO}$ hole transporting layers. Nano Energy 2018, 49, 163-171. [CrossRef]

15. Zhang, H.; Cheng, J.; Lin, F.; He, H.; Mao, J.; Wong, K.S.; Jen, A.K.Y.; Choy, W.C.H. Pinhole-free and surface-nanostructured niox film by room-Temperature solution process for high-performance flexible perovskite solar cells with good stability and reproducibility. ACS Nano 2016, 10, 1503-1511. [CrossRef] [PubMed]

16. Yin, X.; Chen, P.; Que, M.; Xing, Y.; Que, W.; Niu, C.; Shao, J. Highly Efficient Flexible Perovskite Solar Cells Using Solution-Derived NiOx Hole Contacts. ACS Nano 2016, 10, 3630-3636. [CrossRef]

17. Liu, S.; Liu, R.; Chen, Y.; Ho, S.; Kim, J.H.; So, F. Nickel oxide hole injection/transport layers for efficient solution-processed organic light-emitting diodes. Chem. Mater. 2014, 26, 4528-4534. [CrossRef]

18. He, Q.; Yao, K.; Wang, X.; Xia, X.; Leng, S.; Li, F. Room-Temperature and Solution-Processable Cu-Doped Nickel Oxide Nanoparticles for Efficient Hole-Transport Layers of Flexible Large-Area Perovskite Solar Cells. ACS Appl. Mater. Interfaces 2017, 9, 41887-41897. [CrossRef]

19. Chen, W.; Liu, F.-Z.; Feng, X.-Y.; Djurišić, A.B.; Chan, W.K.; He, Z.-B. Cesium Doped NiO x as an Efficient Hole Extraction Layer for Inverted Planar Perovskite Solar Cells. Adv. Energy Mater. 2017, 7, 1700722. [CrossRef]

20. Jung, J.W.; Chueh, C.C.; Jen, A.K.Y. A Low-Temperature, Solution-Processable, Cu-Doped Nickel Oxide Hole-Transporting Layer via the Combustion Method for High-Performance Thin-Film Perovskite Solar Cells. Adv. Mater. 2015, 27, 7874-7880. [CrossRef]

21. Sun, X.; Li, B.; Metiu, H. Ethane activation by Nb-doped NiO. J. Phys. Chem. C 2013, 117, 23597-23608. [CrossRef]

22. Hu, Z.; Chen, D.; Yang, P.; Yang, L.; Qin, L.; Huang, Y.; Zhao, X. Sol-gel-processed yttrium-doped NiO as hole transport layer in inverted perovskite solar cells for enhanced performance. Appl. Surf. Sci. 2018, 441, 258-264. [CrossRef] 
23. Jun-Dar, H.; Wang-Ting, H.; Bo-Yu, L.; Yu-Ting, H.; Shr-Ting, W. Effect of Ag-doping on the characteristics of $\mathrm{Ag}_{\mathrm{x}} \mathrm{Ni}_{1-\mathrm{x}} \mathrm{O}$ transparent conducting oxide film and their applications in heterojunction diodes. J. Phys. D Appl. Phys. 2020, 53, 275107.

24. Sharma, R.; Yadav, K. Effect of lattice defects on the structural and optical properties of Ni1-XAgXO (where $\mathrm{X}=0.0,0.01,0.03,0.05,0.10$ and 0.15) nanoparticles. Appl. Phys. A Mater. Sci. Process. 2018, 124. [CrossRef]

25. Xie, Y.; Lu, K.; Duan, J.; Jiang, Y.; Hu, L.; Liu, T.; Zhou, Y.; Hu, B. Enhancing Photovoltaic Performance of Inverted Planar Perovskite Solar Cells by Cobalt-Doped Nickel Oxide Hole Transport Layer. ACS Appl. Mater. Interfaces 2018, 10, 14153-14159. [CrossRef]

26. Keraudy, J.; Ferrec, A.; Richard-Plouet, M.; Hamon, J.; Goullet, A.; Jouan, P.Y. Nitrogen doping on NiO by reactive magnetron sputtering: A new pathway to dynamically tune the optical and electrical properties. Appl. Surf. Sci. 2017, 409, 77-84. [CrossRef]

27. Chen, P.C.; Yang, S.H. Potassium-Doped Nickel Oxide as the Hole Transport Layer for Efficient and Stable Inverted Perovskite Solar Cells. ACS Appl. Energy Mater. 2019, 2, 6705-6713. [CrossRef]

28. Islam, M.B.; Yanagida, M.; Shirai, Y.; Nabetani, Y.; Miyano, K. NiO x Hole Transport Layer for Perovskite Solar Cells with Improved Stability and Reproducibility. ACS Omega 2017, 2, 2291-2299. [CrossRef]

29. Kwon, U.; Kim, B.-G.; Nguyen, D.C.; Park, J.-H.; Ha, N.Y.; Kim, S.-J.; Ko, S.H.; Lee, S.; Lee, D.; Park, H.J. Solution-Processible Crystalline NiO Nanoparticles for High-Performance Planar Perovskite Photovoltaic Cells. Sci. Rep. 2016, 6, 30759. [CrossRef]

30. AlFaify, S.; Shkir, M. A facile one pot synthesis of novel pure and Cd doped PbI2 nanostructures for electro-optic and radiation detection applications. Opt. Mater. 2019, 88, 417-423. [CrossRef]

31. Geng, X.; Lahem, D.; Zhang, C.; Li, C.-J.; Olivier, M.-G.; Debliquy, M. Visible light enhanced black NiO sensors for ppb-level NO2 detection at room temperature. Ceram. Int. 2019, 45, 4253-4261. [CrossRef]

32. Xia, X.; Jiang, Y.; Wan, Q.; Wang, X.; Wang, L.; Li, F. Lithium and Silver Co-Doped Nickel Oxide Hole-Transporting Layer Boosting the Efficiency and Stability of Inverted Planar Perovskite Solar Cells. ACS Appl. Mater. Interfaces 2018, 10, 44501-44510. [CrossRef] [PubMed]

(C) 2020 by the authors. Licensee MDPI, Basel, Switzerland. This article is an open access article distributed under the terms and conditions of the Creative Commons Attribution (CC BY) license (http://creativecommons.org/licenses/by/4.0/). 